\title{
Toxin production by Aeromonas spp. from different sources
}

\author{
SALLY E. MILLERSHIP, M. R. BARER* and SOAD TABAOCHALI \\ Department of Microbiology, St Bartholomew's Hospital, West Smithfield, London EC1A 7BE and \\ *Department of Medical Microbiology, London School of Hygiene and Tropical Medicine, Keppel St., \\ London WC1E 7 HT
}

\begin{abstract}
Summary. One hundred and eleven isolates of Aeromonas from water and from human sources were identified to species level and tested for the production of cytotoxin. These results were correlated with the source of each isolate and, for those from human faeces, with the clinical history of diarrhoea. $A$. caviae predominated in water, comprising 16 of 32 isolates; only one isolate from water was $A$. sobria. In human faecal samples 21 of 76 isolates were $A$. sobria; this was a significant difference. Cytotoxin producing strains were significantly more common in patients with no known cause for their gut symptoms. It is concluded that gastro-enteritis caused by Aeromonas is related to species and to production of cytotoxin.
\end{abstract}

\section{Introduction}

Aeromonas spp. cause various diseases in man, including wound infections and septicaemia in immunocompromised patients (Abrams et al., 1971; McCracken and Barkley, 1972; Washington, 1972). Most isolates have been from faeces and some studies have suggested that they are a cause of gastro-enteritis (Chatterjee and Neogy, 1972; Cumberbatch et al., 1979; Gracey et al., 1982; Pitarangsi et al., 1982; Janda et al., 1983) but others have refuted this possibility (Catsaras and Buttiaux, 1965; Bhat et al., 1974; Millership et al., 1983). Some strains may be more virulent than others and in this respect division of the genus into species would be a step towards identifying virulent isolates.

Recent studies (Janda et al., 1984; Turnbull et al., 1984) based on the work of Popoff and Véron (1976) have divided Aeromonas into three species- $A$. sobria, A. hydrophila and A. caviae. A DNA homology study confirmed this division although each species may contain three subspecies indistinguishable phenotypically (Popoff et al., 1981). There is already some evidence that $A$. sobria is more likely to be a pathogen in man (Daily et al., 1981; Watson et al., 1985) and a relationship between species and enterotoxin production

Received 12 Jan. 1986; revised version accepted 10 Feb. 1986.

*Correspondence and requests for offprints should be sent to $\mathrm{Dr}$ M. R. Barer. detected in animal models has been demonstrated (Turnbull et al., 1984).

Reports on the exotoxins of Aeromonas are very confused, particularly in relation to pathogenicity in the gut. Some workers have claimed the existence of a relatively heat stable cytotonic enterotoxin (Ljungh et al., 1977) and the gene coding for this product has been cloned (Chakraborty et al., 1984). Others have been unable to detect any specific heat stable activity in cell culture (Cumberbatch et al., 1979) although non-specific cell rounding effects were found.

There is no doubt about the existence of a heatlabile $\left(56^{\circ} \mathrm{C}\right)$ cytotoxin. Most reports of animal studies have noted the heat lability of enterotoxin (Burke et al., 1981; Johnson and Lior, 1981; Turnbull et al., 1984) and it is quite likely that these assays have detected the cytotoxin. Further support for this view is provided by the work of Asao et al. (1984) who purified a haemolysin with a mol. wt corresponding to the $\beta$ haemolysin of Ljungh et al. (1981). This substance had cytotoxic activity in Vero cells and enterotoxic effects in the infant mouse and rabbit ileal-loop tests. A second haemolysin, $\alpha$, has also been described (Ljungh et al., 1981) but it is only produced in the stationary phase of growth and little work has been done on it.

The aims of the following study were to correlate species with source for a large number of isolates of Aeromonas, and to examine cytotoxin production and relate species and toxin production to clinical history of human isolates. 


\section{Materials and methods}

\section{Bacterial strains}

One hundred and eleven isolates were examined. All but one were from north-east London or from the City of London. Twenty four were environmental isolates from taps, swimming pools and other chlorinated supplies; eight were from untreated pools and streams; and 79 were human isolates, all but three from faeces.

Initial isolation with identification was done by methods previously described (Millership et al., 1983; Millership and Chattopadhyay, 1985). Faecal specimens were enriched in alkaline peptone water and subcultured to xylose-deoxycholate-citrate agar or to bile salts-brilliant green agar. All specimens were also examined for Salmonella, Shigella, Campylobacter and, where indicated, for enteropathogenic Escherichia coli, Staphylococcus aureus, Clostridium perfringens, $C$. difficile and ova, cysts and parasites by standard methods. No virus studies were done. Water specimens were added to alkaline peptone water, or were filtered and the membrane filter incubated on bile salts-brilliant green agar. Identification to genus level was completed with API $20 \mathrm{E}$ trays and vibriostatic agent $\mathrm{O} 129$.

Species were defined by the results of up to 13 tests based on the scheme of Popoff and Veron (1976), (Barer et al., 1986).

\section{Toxin studies}

Culture filtrates were prepared as described by Barer $e t$ al. (1986). Overnight shake cultures in tryptone-soya broth with yeast extract were centrifuged and filtered through a $0.45-\mu \mathrm{m}$ membrane filter (Millipore). Cytotoxic activity was studied in Vero cells.

\section{Clinical histories}

As much clinical information as possible was gathered whenever a faecal specimen yielded Aeromonas. For hospital patients, details were obtained from the notes and by visiting the patient. When sample examination was requested by general practitioners or by the public health inspectorate, details were taken from the specimen request form and, where possible, further details were obtained from the patient's general practitioner.

Patients were then divided into four categories. Those who had had an episode of diarrhoea or vomiting (or both) within the previous 28 days (or if this information was not available, those whose sample was the first one submitted for investigation of these complaints) without any other cause for gastro-intestinal disease were placed in class A. Patients who had another cause, either infective or non-infective, were placed in class B. Those with no history of gastro-intestinal upset were in class $\mathrm{C}$ and when no history was available patients were placed in class $\mathbf{D}$.

Statistical analyses were by $\chi^{2}$ or Fisher's exact tests.

\section{Results}

Table I shows the numbers of each species isolated from human and environmental sources. $A$. sobria was rare in water samples but $28 \%$ of the isolates from faeces belonged to this species. The predominant species in water samples was $A$. caviae. However, there was little difference between the proportions of cytotoxin producers amongst strains isolated from the environment $(28 \%)$ and from human sources $(29 \%)(p>0 \cdot 8)$.

When human faecal isolates were grouped according to clinical history (table II), there was an excess of $A$. sobria (36\%) from those patients with no other known cause for their diarrhoea compared with those with no symptoms $(15 \%)$, but the difference was not significant $(0 \cdot 2>p>0 \cdot 1)$ There were, however, significant differences between the proportions of patients in groups $\mathrm{A}, \mathrm{B}$ and $\mathrm{C}$ with cytotoxin-producing strains in their stools $\left(\chi^{2}=6 \cdot 3\right.$, $\mathrm{df}=2, \mathrm{p}<0.05)$. The largest difference was between group A (45\% toxigenic) and group C (15\% toxige-

Table I. Aeromonas species isolated from human and environmental sources

\begin{tabular}{|c|c|c|c|c|}
\hline \multirow[b]{2}{*}{ Species } & \multicolumn{4}{|c|}{ Number of strains isolated from } \\
\hline & $\begin{array}{l}\text { human } \\
\text { faeces }\end{array}$ & $\begin{array}{l}\text { other human } \\
\text { sources }\end{array}$ & $\begin{array}{c}\text { chlorinated } \\
\text { water }\end{array}$ & $\begin{array}{l}\text { untreated } \\
\text { water }\end{array}$ \\
\hline A. hydrophila & $9(3)^{*}$ & $1(1)$ & $9(7)$ & $3(1) \dagger$ \\
\hline A. caviae & $42(0)$ & $1(0)$ & $11(0)$ & $5(0)$ \\
\hline A. sobria & $21(18)$ & $1(1)$ & $1(1)$ & $0(0)$ \\
\hline Aeromonas group 4 & $4(0)$ & $0(0)$ & $3(0)$ & $0(0)$ \\
\hline Total & $76(21)$ & $3(2)$ & $24(8)$ & $8(1)$ \\
\hline
\end{tabular}

* Numbers in parentheses are numbers of toxigenic strains.

+ One strain was not tested for toxin production. 
Table II. Relationship of species and toxin production to clinical history in Aeromonas isolates from human faeces

\begin{tabular}{lcrrrr}
\hline & \multicolumn{2}{c}{$\begin{array}{c}\text { Number of } \\
\text { from patient group }\end{array}$} \\
\cline { 2 - 6 } Species & \multicolumn{1}{c}{ A } & \multicolumn{1}{c}{ B } & \multicolumn{1}{c}{ C } & D \\
\hline A. hydrophila & $3(2)^{*}$ & $4(1)$ & $2(1)$ & $0(0)$ \\
A. caviae & $10(0)$ & $15(0)$ & $13(0)$ & 1 & $(0)$ \\
A. sobria & $8(8)$ & $8(5)$ & $3(2)$ & $2(2)$ \\
Aeromonas group 4 & $1(0)$ & $2(0)$ & $2(0)$ & 1 & $(0)$ \\
Total & $22(10)$ & $31(6)$ & $20(3)$ & $3(2)$
\end{tabular}

A, B, C and D-see Materials and methods.

* Numbers in parentheses are numbers of toxin producing strain.

nic). All but four toxin-producing strains produced cytotoxin in titres or at least 400 and up to 10000 . Two strains with titres of $<100$ were from patients in group C. Of the faecal isolates, $41 \%$ came from patients in group B who had other bowel pathology; $19 \%$ of these strains produced cytotoxin.

Nineteen isolates were found on direct plating and the results obtained with these strains are analysed in table III. Although the numbers are small it is notable that no cytotoxin-producing strains occurred in patients without gastro-intestinal symptoms in numbers detectable by direct plating.

\section{Discussion}

Aeromonads are not uncommon even in treated tap water (Burke et al., 1984; Millership and Chattopadhyay, 1985) and it seems likely that faecal isolates are acquired from this source. The distribution of species amongst faecal isolates is, therefore, surprising given the excess of $A$. caviae in environmental samples. It suggests that $A$. sobria has a greater potential for colonising the gastro-intestinal tract. There is some experimental evidence to support this view; Watson et al. (1985) found that of a group of Aeromonas isolates the majority of strains invasive in vitro were $A$. sobria Clearly colonisation must precede invasion.

A few cytotoxigenic strains of Aeromonas were found in healthy people but most were from persons with gastro-intestinal symptoms, particularly those who were previously healthy. The cytotoxin has been noted to have enterotoxin activity (Asao et al., 1984) and it would appear that it is at least a marker of pathogenicity, whatever the role of any cytotonic enterotoxin. The finding of toxigenic strains in healthy people is not unexpected. Other enteropathogens, such as $E$. coli, require several virulence factors to produce disease (Lancet, 1983). It is also notable that two of the three strains in this category were poor toxin producers in vitro.

If the cytotoxin is a virulence factor it is necessary to explain the number of non-toxin producers from patients with no other explanation for their diarrhoea. There are several possible factors involved. Toxin production in vitro varies with the conditions of culture and of assay (Burke et al., 1981; Ljungh et al., 1981). A high proportion of patients with other bowel disease, in particular those due to other bacterial pathogens, has been noted amongst Aeromonas-positive patients (Shread et al., 1981) and there is some evidence that Aeromonas occurs most often in water sources contaminated with other pathogens (Millership and Chattopadhyay, 1985). Bowel mucosa already damaged may be predisposed to colonisation by aeromonads that are not necessarily pathogenic.

The discrepancies in previous studies of the pathogenicity of Aeromonas may be explained by the methods of isolation used. Direct plating only detects Aeromonas when large numbers are present in a faecal specimen. Most enteric pathogens become the predominant bowel flora when they cause acute disease and it might be expected that only strains of Aeromonas causing diarrhoea will be found without use of an enrichment medium. None of the studies in which "enterotoxin" producing Aeromonas have been isolated almost exclusively from diarrhoeal stools have used an enrichment technique (Gracey et al., 1982; Pitarangsi et al., 1982; Janda et al., 1983; Agger et al., 1985). Although the numbers are small the re-analysis of our results in table III conforms to this pattern.

Table III. Aeromonas isolates from human faeces obtained by direct plating alone

\begin{tabular}{|c|c|c|c|}
\hline \multirow[b]{2}{*}{ Species } & \multicolumn{3}{|c|}{$\begin{array}{c}\text { Number of strains } \\
\text { isolated from patient } \\
\text { group }\end{array}$} \\
\hline & $A$ & B & $\mathrm{C}$ \\
\hline A. hydrophila & $0(0)^{*}$ & $1(0)$ & $0(0)$ \\
\hline A. caviae & $3(0)$ & $3(0)$ & $4(0)$ \\
\hline A. sobria & $4(4)$ & $4(2)$ & $0(0)$ \\
\hline Aeromonas group 4 & $0(0)$ & $0(0)$ & $0(0)$ \\
\hline Total & 7 (4) & $8(2)$ & $4(0)$ \\
\hline
\end{tabular}

A, B and C-see Materials and methods. * Numbers in parentheses are numbers of toxin-producing strains. 
Thus it appears that only some isolates of Aeromonas belonging to the species sobria and hydrophila are associated with diarrhoea. Epidemiological studies are unlikely to give a clear-cut answer to the question of whether Aeromonas is an

\section{REFERENCES}

Abrams E, Zierdt C H, Brown J A 1971 Observations on Aeromonas hydrophila septicaemia in a patient with leukaemia. Journal of Clinical Pathology 24:491-492.

Agger W A. McCormick J D, Gurwith M 1985 Clinical and microbiological features of Aeromonas hydrophila-associated diarrhea. Journal of Cinical Microbiology 21:909. 913.

Asao T. Kinoshita Y. Kozaki S, Uemura T. Sakaguchi G 1984 Purification and some properties of Aeromonas hydrophila hemolysin. Infection and Immunity 46:122-127.

Barer MR, Millership SE. Tabaqchali S 1986 Relationship of toxin production to species in the genus Aeromonas. Journal of Medical Microbiology 22:303-309.

Bhat P. Shanthakumari S. Rajan D 1974 The characterisation and significance of Plesiomonas shigelloides and Aeromonas hidrophila isolated from an epidemic of diarrhoea. Indian Journal of Medical Research 62:1051-1060.

Burke V. Robinson J, Berry R J, Gracey M 1981 Detection of enterotoxins of Aeromonas hydrophila by a suckling-mouse test. Journal of Medical Microbiology 14:401-408.

Burke V, Robinson J, Gracey M, Peterson D, Partridge K 1984 Isolation of Aeromonas hydrophila from a metropolitan water supply: seasonal correlation with clinical isolates. Applied and Environmental Microbiology 48:361-366.

Catsareas M, Buttiaux R 1965 Lés Aeromonas dans les matiéres fécales humaines. Annales de L'Institut Pasteur de Lille 16:85-88.

Chakraborty T, Montenegro M A. Sanyal S C, Helmuth R. Bulling E, Timmis K N 1984 Cloning of enterotoxin gene from Aeromonas hydrophila provides conclusive evidence of production of a cytotonic enterotoxin. Infection and Immunity 46:435 441 .

Chatterjee B D, Neogy K N 1972 Studies on Aeromonas and Plesiomonas species isolated from cases of choleraic diarrhoea. Indian Journal of Medical Research 60:520-524.

Cumberbatch N, Gurwith M J, Lanston C, Bradley Sack R. Brunton J 1979 Cytotoxic enterotoxin produced by Aeromonas hydrophila: relationship of toxigenic isolates to diarrheal disease. Infection and Immunity 23:829 837.

Daily O P et al. 1981 Association of Aeromonas sobria with human infection. Journal of Clinical Microbiology 13:769 777

Gracey M. Burke V. Robinson J 1982 Aeromonas-associated gast roenteritis. Lancet 2:1304-1306.

Janda J M, Bottone E J, Skinner C V, Calcaterra D 1983 Phenotypic markers associated with gastrointestinal Aeromonas hydrophila isolates from symptomatic children. Journal of Clinical Microbiology 17:588-591. enteric pathogen or not in the absence of a detailed analysis of the virulence factors involved.

We thank the Wellcome Trust for financial support (MRB) and Ms H. Staley for technical assistance.

Janda J M, Reitano M, Bottone E J 1984 Biotyping of Aeromonas isolates as a correlate to delineating a speciesassociated disease spectrum. Journal of Clinical Microbiology 19:44 47 .

Johnson W M, Lior H 1981 Cytotoxicity and suckling mouse reactivity of Aeronomas hydrophila isolated from human sources. Canadian Journal of Microbiology, 27:1019-1027.

Lancet (Leading article) 1983 Mechanisms in enteropathogenic Escherichia coli diarrhoea. Lancet 1:1254-1256.

Ljungh A, Popoff M, Wadstrom T 1977 Aeromonas hydrophila in diarrheal disease: detection of enterotoxin and biotyping of strains. Journal of Clinical Microbiology 6:96-100.

Ljungh A, Wretlind B, Molby R 1981 Separation and characterisation of enterotoxin and two haemolysins from Aeromonas hydrophila. Acta Pathologica et Microbiologica Scandinavica Section B 89:387-397.

McCracken A W, Barkley R 1972 Isolation of Aeromonas species from clinical sources. Journal of Clinical Pathology 25:970 975.

Millership S E, Curnow S R, Chattopadhyay B 1983 Faecal carriage rate of Aeromonas hydrophilia. Journal of Clinical Pathology 36:920-923.

Millership S E, Chattopadhyay B 1985 Aeromonas hydrophila in chlorinated water supplies. Journal of Hospital Infection 6:75-80.

Pitarangsi C et al. 1982 Enteropathogenicity of Aeromonas hydrophila and Plesiomonas shigelloides: prevalence among individuals with and without diarrhea in Thailand. Infection and Immunity 35:666-673.

Popoff M Y, Coynault C, Kiredjian M, Lemelin M 1981 Polynucleotide sequence relatedness among motile Aeromonas species. Current Microbiology 5:109-114.

Popoff M. Véron H 1976 A taxonomic study of the Aeromonas hydrophila-Aeromonas punctata group. Journal of General Microbiology 94:11-22.

Shread P, Donovan T J, Lee J V 1981 A survey of the incidence of Aeromonas in human faeces. Society for General Microbiology Quarterly 8:184.

Turnbull P C B et al. 1984 Enterotoxin production in relation to taxonomic grouping and source of isolation of Aeromonas species. Journal of Clinical Microbiology 19:175-180.

Washington J A 1972 Aeromonas hydrophila in clinical bacteriologic specimens. Annals of Internal Medicine 76:611-614.

Watson I M, Robinson J O, Burke V, Gracey M 1985 Invasiveness of Aeromonas spp. in relation to biotype. virulence factors and clinical features. Journal of Clinical Microbiology 22:48-51. 